\title{
Single and Partnered Individuals' Sexual Satisfaction as a Function of Sexual Desire and Activities: Results Using a Sexual Satisfaction Scale Demonstrating Measurement Invariance Across Partnership Status
}

\author{
Yoobin Park ${ }^{1}$ (i) $\cdot$ Geoff MacDonald ${ }^{1}$
}

Received: 11 February 2021 / Revised: 10 September 2021 / Accepted: 12 September 2021 / Published online: 8 January 2022

(c) The Author(s), under exclusive licence to Springer Science+Business Media, LLC, part of Springer Nature 2021

\begin{abstract}
Although some evidence exists to suggest that single (i.e., unpartnered) individuals are less sexually satisfied on average than are partnered individuals, it is unclear whether the variables correlating with each group's sexual satisfaction are similar or different. This research sought to examine how desire for and actual engagement in solitary and partnered sexual activities are associated with both groups' sexual satisfaction. We first conducted a preliminary study $(n=572)$ to test and refine existing measures of sexual satisfaction for applicability across relationship status. In two follow-up studies $(N=1,238)$, measurement invariance (across relationship status and gender) of the resulting 4-item sexual satisfaction scale was established. Further, results across the studies showed that for singles dyadic sexual desire was negatively related to sexual satisfaction, whereas no significant link was found with solitary desire. For individuals in romantic relationships, having higher sexual desire involving a partner and lower solitary desire were both associated with greater sexual satisfaction. When analyzing participants' responses on the desired and actual frequency of engaging in specific sexual acts, we found that for both single and partnered individuals, frequent engagement in partnered acts was associated with greater sexual satisfaction. Wanting frequent engagement in partnered acts was associated with lower sexual satisfaction for both groups, but only if the current frequency of engaging in these acts was low. These findings suggest that at least during the COVID-19 pandemic, meeting desires for partnered sex plays an important role in maintaining a sexually satisfying life, regardless of one's relationship status.
\end{abstract}

Keywords Sexual satisfaction $\cdot$ Singlehood $\cdot$ Relationship status $\cdot$ Sexual desire

\section{Introduction}

For many people, sexuality is an integral aspect of their lives that has important implications for their well-being (Diamond \& Huebner, 2012; Gott \& Hinchliff, 2003). However, research regarding the benefits that may arise from satisfaction with one's sexual life has most often been studied in the context of people's romantic relationships, with one of the most well-documented findings being that higher sexual satisfaction is associated with greater happiness or satisfaction in their current relationship (e.g., Fisher et al., 2015; McNulty et al., 2016). Recently, researchers have also drawn attention

Yoobin Park

yoobin.park@mail.utoronto.ca

1 Department of Psychology, University of Toronto, 100 St.

George St., Toronto, ON M5S 3G3, Canada to the sexual lives of unpartnered individuals (referred to as singles hereafter), demonstrating that singles with more satisfying sexual lives report higher life satisfaction and more satisfaction with their single status (Park et al., 2021). However, this research noted the need for a reliable measure of sexual satisfaction that is appropriate for singles' often unpartnered sexual lives and left open the question of what constitutes a satisfying sexual life for singles. In the present research, we attempt to present such a measure and examine the associations of singles' sexual satisfaction with sexual desire and activity, both solitary and partnered. Further, we examine whether these associations are unique among single individuals or similarly observed among partnered individuals. 


\section{Sexuality and Singles' Well-Being}

With the increasing amount of time individuals stay unmarried (e.g., delayed marriage; OECD, 2019) and the rise of one-person households (e.g., in the United States; US Census Bureau, 2020), understanding what a happy life looks like for single individuals has become an important issue for both researchers and the public. One aspect of single individuals' lives that has attracted attention is sexuality (Gray et al., 2019; Lindberg \& Singh, 2008; Rodrigue et al., 2015). In particular, the (relative lack of) availability of sexual opportunities has been considered as one of the factors that "pushes" people away from singlehood and toward marriage (Stein, 1975); later investigations also confirmed that concerns around meeting sexual needs contribute to people's fears of being single (Spielmann et al., 2013) and that people are more satisfied with singlehood when their sexual life is satisfying (Park et al., 2021).

Although these findings suggest that feeling sexually satisfied may be an important contributor to well-being in singlehood, little research exists to shed light on what constitutes a satisfying sex life for singles. Research on single individuals' sexual lives has tended to take one of two foci. First, some research has been descriptive, exploring the frequency of singles' sexual activities (e.g., Beutel et al., 2018) or the type of sexual encounters in which they engage (e.g., Rodrigue et al., 2015). The second focus has been comparing singles' satisfaction and behaviors to those of partnered individuals (e.g., Antičević et al., 2017) or across sexual contexts (e.g., friends with benefits vs. casual hookup; Mark et al., 2015). Although this body of work can speak to what a normative sex life looks like for single individuals, it cannot speak to what a sexually satisfying life looks like for singles.

In the presence of the large body of work on partnered individuals' sexual lives, one might in fact be inclined to think that the same desires and activities that compose partnered individuals' sexually satisfying lives (e.g., less frequent masturbation; Brody \& Costa, 2009) might also mark the lives of sexually satisfied singles. This might be an imprecise assumption if single individuals' sexual enjoyment does indeed entail unique factors from partnered individuals, which would suggest that helping single individuals achieve greater sexual satisfaction also requires a different approach from helping partnered individuals. Indeed, what we know to help improve partnered individuals' sexual lives might not be entirely applicable to single individuals (e.g., improving the non-sexual aspects of the relationship with a partner; Byers, 1999). Overall, gaining insights into what desires and activities normatively relate to single individuals' sexual satisfaction may be helpful for understanding and promoting more satisfying sexual lives for this population, which in turn has implications for their satisfaction regarding singlehood more generally (Park et al., 2021).

\section{Sexual Satisfaction}

As with satisfaction in many other domains, sexual satisfaction has various components to it (e.g., Štulhofer et al., 2010) such that people can be more satisfied with one aspect of their sexual lives than others. In the present research, we operationalize sexual satisfaction as a global judgment of the quality of one's sexual life (see Shaw \& Rogge, 2016). This approach is particularly useful when sexuality research includes a focus on the potential for varieties of sexual domains (e.g., both solitary and partnered activity) that may contribute to sexual satisfaction. That is, given the multiple idiosyncratic paths to sexual gratification for single and partnered individuals, having participants define their own set of criteria in making satisfaction judgments (Suh et al., 1998) may be helpful and perhaps even necessary.

\section{Sexual Desire and Sexual Satisfaction}

Broadly defined as "interest in sexual activity" (Spector et al., 1996), sexual desire is a multidimensional construct. In particular, as sexual activities can be performed either alone or with others, sexual desire can center on solitary or partnered sexual acts (i.e., solitary and dyadic sexual desire, respectively). Empirical research has shown that not only are solitary and dyadic desire only moderately correlated (less than $r=0.40$ in most research; Moyano et al., 2017; Spector et al., 1996; van Anders, 2012), but they also diverge in their relations to other variables (Cappell et al., 2016).

Sexual desire is considered as a motivational state that impels individuals to seek out sexual experiences or more broadly, achieve certain sexual goals (DeLamater \& Sill, 2005; Levine, 2003; Regan \& Berscheid, 1999). As such, much research has been conducted to examine the link between sexual desire and the degree to which the individual feels sexually satisfied (i.e., whether having the strong motivational force is conducive to achieving greater satisfaction). The links between both types of sexual desire (solitary and partnered) and sexual satisfaction are quite clear among partnered individuals. When it comes to dyadic sexual desire, higher sexual desire toward the current partner is associated with greater sexual satisfaction. However, sexual desire involving attractive others more generally (i.e., someone other than the partner) is either not associated with or negatively associated with sexual satisfaction (Mark et al., 2018; Moyano et al., 2017). No significant link has been found between solitary desire and partnered individuals' sexual satisfaction (Mark et al., 2018; Moyano et al., 2017).

However, the link (or lack thereof) between sexual desire and satisfaction is not as clear among singles, given the lack of research conducted exclusively among this population. In the one study that reported single individuals' sexual desire 
separate from partnered individuals' (Chao et al., 2011), single individuals reported lower dyadic sexual desire but similar levels of solitary sexual desire as partnered individuals. However, in examining the link between sexual desire and sexual satisfaction, this study collapsed the sample across partnership status, leaving open the question of whether the link between sexual desire and sexual satisfaction differs across single and partnered individuals. Further, the withingroup links between different aspects of desire (i.e., solitary and dyadic desire) and sexual satisfaction were left unexplored in this study.

\section{The Role of Current Sexual Activities}

Several theoretical perspectives suggest that satisfaction in a specific domain is determined by people's perceptions of how well they are doing relative to standards such as their desires (e.g., Michalos, 1985; Solberg et al., 2002). Based on this idea, researchers have (directly or indirectly) conceptualized sexual satisfaction as a state of having what is desired (Santtila et al., 2007; Willoughby \& Vitas, 2012). For example, in one study by Santilla et al. (2007), participants were divided into three groups based on their responses on desired and actual frequency of sexual behaviors: those whose desired activity level was higher than the current level, those whose desired and current activity levels were equal, and those whose current activity level was higher than desired. The second group, those who were doing sexual behaviors as frequently as they desired, was considered to be the "sexually satisfied" group. ${ }^{1}$

Following this perspective, the link between sexual desire and sexual satisfaction may need to be examined in conjunction with the person's actual sexual experiences. For example, in research by Smith et al. (2011), participants (in a relationship) were explicitly asked if they wanted sex more or less often than had occurred during the past year. Those who had been classified as the "sexually dissatisfied" group based on their responses regarding overall sexual satisfaction with a partner tended to report wanting more sex than they had the past year. This suggests that while having strong desires may be related to a sexually dissatisfying life, this should be particularly (or perhaps only) true of those who currently lack the experiences that can help fulfill their desires.

Although previous research such as Smith et al. (2011) has focused on desire and gratification in terms of partnered

\footnotetext{
${ }^{1}$ Nevertheless, we note the need to be careful about the predictorcriterion overlap in this approach (Mark et al., 2014). That is, predictors of sexual satisfaction should be distinguished from what is being assessed as sexual satisfaction. In our conceptualization, the discrepancy between sexual desire and reality is not an indicator of sexual satisfaction; rather, it is one (of perhaps many) factor that shapes sexual satisfaction defined here as the global evaluation of one's sexual life.
}

sexual acts (and specifically, sexual intercourse), given the presence of both solitary and dyadic desires in an individual, it is worth examining both types of desire and how much each is being met. To our knowledge, only one study has incorporated the desired and actual frequency of sexual activities, both solitary and partnered, in explaining people's sexual satisfaction. In a study by Dosch et al. (2016), partnered men who were high on dyadic desire and activity (but low on solitary desire and activity) were found to be more sexually satisfied than those who were high on both solitary and dyadic desire and activity as well as more sexually satisfied than those who were only high on solitary desire and activity (and low on dyadic desire and activity). Notably, desire and activity largely covaried in each of these profiles (i.e., participants reported greater desire for the activities in which they were engaging) and the interplay between the two could not be precisely examined given the researchers' analytic strategy. In the present research, we examine how desire and activity are uniquely and interactively related to sexual satisfaction among both single and partnered individuals. By simultaneously looking at both solitary and dyadic desire and activities, we can get a more comprehensive picture of what a sexually satisfying life looks like; by examining these links in both single and partnered individuals, we can better examine whether a sexually satisfying life comprises different desires and activities for the two groups.

\section{Research Overview}

Two primary research questions for this exploratory research were as follows: (1) how are solitary and dyadic sexual desire associated with single individuals' sexual satisfaction? and (2) are these associations moderated by the extent of actual sexual experiences? In addressing the first question, we took two different approaches to capture the two types of sexual desire. First, we used the solitary and dyadic desire subscales from a well-established measure, Sexual Desire Inventory-2 (Spector et al., 1996), which captures various facets of desire (by asking about participants' perceived strength of desire compared to others, frequency of sexual thoughts, importance of sex, etc.). Second, we focused on the desired frequency of sexual activities and asked our participants how frequently they want to engage in a variety of sexual acts. The benefit of this approach was that it allowed us to precisely get at the "reality" counterpart of the desire (i.e., participants reported how frequently they actually engage in the same list of acts), which was necessary to address the second research question. Thus, using the latter operationalization of sexual desire, we were able to examine how desire and reality are interactively associated with sexual satisfaction. In addressing both questions, we also conducted identical analyses among partnered individuals in order to gain insights as to how unique any associations we find are to single individuals 
or whether they may be more general features of sexual satisfaction. Given the lack of research precisely investigating the interactive effects of interest (i.e., the second research question) among partnered individuals, we did not make a priori predictions as to how single and partnered individuals would differ.

Prior to addressing our research questions, one challenge we faced was finding a sexual satisfaction scale that was suitable for use with both single and partnered individuals - that is, a scale of which measurement invariance across relationship status has been tested and established. Measurement invariance indicates that a given instrument assesses identical constructs across different groups (Milfont \& Fischer, 2010). This property of a measure is critical when trying to interpret any between-group differences because if the measure is not invariant, we cannot assume we are comparing the same construct across the two groups. That is, we cannot distinguish the meaningful differences of interest from the groups' differences in psychometric responses to the measure (Sakaluk, 2019).

Most existing sexual satisfaction scales (e.g., Global Measure of Sexual Satisfaction; Lawrance \& Byers, 1995, Index of Sexual Satisfaction; Hudson et al., 1981) were developed in the context of romantic relationships and thus are suitable primarily for use among partnered individuals. This is evident in that most sexual satisfaction scales include items that assume the presence of a partner (e.g., "I feel that my partner enjoys our sex life"), which may not be equivalently meaningful across single and partnered individuals. Thus, in a preliminary study, we compiled items from multiple existing scales into a scale of sexual satisfaction demonstrating measurement invariance across relationship status. We used the newly compiled measure to address our primary research questions in Studies 1 and 2. Note that all our data were collected during the COVID-19 pandemic and we discuss the potential impact of COVID conditions in our data in the General Discussion. None of the data used in this research has been reported elsewhere.

\section{Preliminary Study}

\section{Method}

\section{Participants and Procedure}

Data for this study were collected during the first week of June 2020. Participants were recruited via Prolific, an online crowdsourcing platform. We targeted recruitment of 600 participants based on previous recommendations (for conducting EFA or IRT analyses; Edelen \& Reeve, 2007; Howard, 2016) and equal numbers of single and partnered individuals. Among the 601 participants who completed the survey, five failed an attention check, two reported having been dishonest in answering the questions, and 22 participants did not want their data to be used. After excluding these individuals, our final sample consisted of 572 participants (363 men, 201 women, 3 transgender, and 5 unidentified) who were on average 27.2 years old $(S D=8.05$; range $=18$ to 61 ). The sample included 293 individuals currently in a relationship who reported having been with the partner for an average of 4 years and 11 months ( $S D=6$ years and 4 months; range $=2$ weeks to 40 years). About half of the partnered individuals $(n=152)$ were dating, 81 were married and 60 were engaged.

\section{Results}

Our initial item pool consisted of 15 items selected from existing scales that had items related to global evaluations of individuals' sexual lives (Meston \& Trapnell, 2005; Neto \& da Conceição Pinto, 2013; Nomejko \& Dolińska-Zygmunt, 2014; Snell \& Papini, 1989; Snell et al., 1993; Symonds et al., 2005). Our goal was to retain four items (a minimum number of items considered to be adequate from the model identification perspective; Yang et al., 2010) that function similarly across gender and relationship status and have the most informational value (i.e., can discriminate individuals with varying levels of sexual satisfaction). To this end, we conducted an item response theory (IRT) analysis.

We examined the unidimensionality of the items by conducting an exploratory factor analysis, and the presence of local dependence by using both the Q3 statistic (Yen, 1984) and Jackknife Slope Index (Edwards et al., 2018). We tested invariance across gender and relationship status through an IRT-based differential item functioning analyses (Choi et al, 2011). Items were dropped if they showed local dependence or were flagged to be functioning differently across men and women or single and partnered individuals. Items that demonstrated significant misfit (based on $\mathrm{S}-\mathrm{X}^{2}$ statistic; Orlando \& Thissen, 2003) were also dropped. A full list of the initial item pool as well as detailed results of the analyses can be found in Supplemental Material. A final set of four items is shown in Table $1(\alpha=0.96)$. Notably, three of the four items in this final set were from Neto and da Conceição Pinto's (2013) Satisfaction with Sex Life Scale, whereas the fourth was from Snell et al. (1993).

\section{Study 1}

The first aim of Study 1 was to examine whether the newly compiled items of sexual satisfaction (Satisfaction with Sex Life Scale-Revised) function similarly across relationship status (as well as gender) and test mean-level differences 
Table 1 Final items for the Satisfaction with Sex Life Scale—Revised and descriptive statistics

\begin{tabular}{|c|c|c|c|c|c|}
\hline Items & $\begin{array}{l}\text { All } \\
\text { M (SD) }\end{array}$ & $\begin{array}{l}\text { Single } \\
\text { M (SD) }\end{array}$ & $\begin{array}{l}\text { Partnered } \\
\text { M (SD) }\end{array}$ & $\begin{array}{l}\text { Men } \\
\text { M (SD) }\end{array}$ & $\begin{array}{l}\text { Women } \\
\text { M (SD) }\end{array}$ \\
\hline 1. In most ways, my sexual life is close to my ideal & $3.65(1.94)$ & $2.78(1.73)$ & $4.47(1.75)$ & $3.52(1.91)$ & $3.88(1.96)$ \\
\hline 2. The conditions of my sexual life are excellent & $3.73(1.91)$ & $2.81(1.66)$ & $4.59(1.72)$ & $3.60(1.91)$ & $3.95(1.89)$ \\
\hline 3. I am satisfied with my sexual life & $4.03(1.88)$ & $3.20(1.75)$ & $4.83(1.64)$ & $3.90(1.86)$ & $4.25(1.89)$ \\
\hline 4. My sexual life meets my expectations & $3.90(1.89)$ & $3.08(1.75)$ & $4.68(1.68)$ & $3.75(1.87)$ & $4.11(1.90)$ \\
\hline
\end{tabular}

$M=$ mean; $\mathrm{SD}=$ standard deviation. Items were assessed on a 7-point scale. The following instruction was presented to the participants: "Please indicate how well each statement reflects your thoughts and feelings about your sex life (including all the sexual activities you may or may not be engaging in)."

across the groups when they do. The second aim of this study was to examine how wanting and performing solitary and dyadic sexual activities were associated with sexual satisfaction among single and partnered individuals. We first examined the link between sexual desire and sexual satisfaction using SDI-2 (Spector et al., 1996). Then, to examine the role of both the desire and actual activities in both single and partnered individuals' evaluation of their sexual lives, we focused on the frequency of wanting and engaging in a variety of activities. Specifically, we created a list of solitary and dyadic sexual activities and asked participants to rate how frequently they want to ("want") and currently do engage ("do") in each. We then examined the interplay between the wants and $d o$ s in relation to sexual satisfaction.

\section{Method}

\section{Participants and Procedure}

Data for this study were collected during the last week of June 2020. We aimed to recruit 500 participants via Prolific (considered to be adequate for measurement invariance testing; Chen, 2007), with an equal number of single and partnered participants. At the end of the data collection, the number of participants who failed attention checks was inspected and these cases were immediately replaced with additional recruitment. In total, 537 participants were recruited. We excluded those who failed attention checks $(n=39)$, who reported having been dishonest in answering the questions $(n=1)$, or who did not want their data to be used $(n=8)$. No other exclusion criteria were applied. The final sample consisted of 489 participants (264 men, 223 women, 2 unidentified) who were 27.81 years old on average $(S D=9.71$; range $=18$ to 70$)$. Half of the participants $(n=243 ; 110$ men, 132 women, 1 unidentified) were currently in a relationship, with an average relationship length of 5 years and a month ( $S D=6$ years and 10 months; range $=1$ month to 47 years). Many participants were dating $(n=140)$, and some were married $(n=60)$ or engaged $(n=42)$. All participants read detailed study descriptions at the end of the survey.

\section{Measures}

Full measure descriptions can be found at https://osf.io/ yda5q.

Sexual Satisfaction We used the four items in Table 1 to assess sexual satisfaction $(\alpha=0.97)$.

Sexual Desire Sexual Desire Inventory-2 (Spector et al., 1996) was used to assess sexual desire. The scale includes items assessing solitary desire (e.g., "How strong is your desire to engage in sexual behavior by yourself?"; $\alpha=0.90$ ) and dyadic desire. Consistent with previous research (Moyano et al., 2017), we differentiated partner-specific dyadic desire ("How strong is your desire to engage in sexual activity with a partner?"; $\alpha=0.90$ ) from attractive-other dyadic desire ("When you first see an attractive person, how strong is your sexual desire?"; $\alpha=0.90$ ) when computing scores for partnered individuals. For single individuals' surveys, we switched the word "a partner" to "someone" (e.g., "How strong is your desire to engage in sexual activity with someone"; $\alpha=0.89$ ) in order to avoid confusion as to whether partner referred to a sexual partner or a committed romantic partner. Particularly given this adaptation, the distinction between partner-specific and attractive-other dyadic desire is unclear among single individuals, and we only computed one scale of dyadic desire using all dyadic items (note that we also confirmed the two-dimensional structure of the SDI among singles in an EFA). Items were rated on 8-point or 9-point scales with anchors corresponding to each question.

Desire for and Engagement in Specific Sexual Acts A list of 25 sexual acts was drafted based on previous literature (e.g., Blunt-Vinti et al., 2019). Participants rated how often they want to do each act as well as how often they are currently doing each act on 7-point scales ranging from 1 (not at all) to 7 (a lot). The list included partnered sexual activities such as "kissing someone" as well as solitary activities such as "sexually touching myself (e.g., masturbating)." Following separate EFA for "want" and "do" list of the activities, we 
Table 2 Correlations between the study variables (Study 1)

\begin{tabular}{lllllllll}
\hline Variables & 1 & 2 & 3 & 4 & 5 & 6 & 7 & 8 \\
\hline 1. Sexual satisfaction & - & $-.19^{* *}$ & $.33^{* *}$ & -.11 & -.11 & .03 & $-.23^{* *}$ & $.53^{* *}$ \\
2. Solitary sexual desire & $-.16^{* *}$ & - & $.29^{* *}$ & $.42^{* *}$ & $.73^{* *}$ & $.44^{* *}$ & $.81^{* *}$ & .11 \\
3. Dyadic sexual desire & $-.35^{* *}$ & $.43^{* *}$ & - & $.24^{* *}$ & $.18^{* *}$ & $.51^{* *}$ & $.16^{* \dagger}$ & $.41^{* *}$ \\
4. Dyadic sexual desire (Other) & - & - & - & - & $.23^{* *}$ & $.22^{* *}$ & $.26^{* *}$ & .10 \\
5. Desired frequency of SSA & .01 & $.68^{* *}$ & $.20^{* *}$ & - & - & $.44^{* *}$ & $.81^{* *}$ & .11 \\
6. Desired frequency of PSA & $-.31^{* *}$ & $.37^{* *}$ & $.66^{* *}$ & - & $.25^{* *}$ & - & $.44^{* *}$ & $.48^{* *}$ \\
7. Actual frequency of SSA & $-.14^{*}$ & $.65^{* *}$ & $.30^{* *}$ & - & $.66^{* *}$ & $.35^{* *}$ & - & .10 \\
8. Actual frequency of PSA & $.25^{* *}$ & .01 & .12 & - & .12 & $.21^{* *}$ & .10 & - \\
\hline
\end{tabular}

SSA = solitary sexual activities; PSA = partnered sexual activities. Dyadic sexual desire refers to overall dyadic sexual desire for singles and partner-specific desire for partnered individuals. Values below the diagonal indicate correlations among singles and values above the diagonal indicate correlations among partnered individuals

${ }^{\dagger}$ Not significant when adjusting for the false discovery rate (Benjamini \& Hochberg, 1995)

$* p<.05, * * p<.01$

retained two factors consisting of ten items for partnered sexual acts and two items for solitary sexual acts (see Supplemental Material for the full and reduced list of the acts).

\section{Statistical Analyses}

We first examined the zero-order correlations of all study variables (Table 2). We then tested for measurement invariance to ensure that our new scale assesses the same construct for those with or without a romantic partner as well as for men and women. Measurement invariance was tested at three levels: (a) configural invariance (i.e., whether the pattern of loadings is the same across the two groups), (b) metric invariance (i.e., whether the magnitude of factor loadings is the same), and (c) scalar invariance (i.e., whether the item intercepts are the same) ${ }^{2}$ Once scalar invariance was achieved (Milfont \& Fischer, 2010), latent mean comparisons were made across the groups by setting one group's mean to 0 and allowing the other group's mean to vary.

Inferences Given the number of significance tests in this exploratory research, we used the Benjamini-Hochberg ("BH") method (Benjamini \& Hochberg, 1995) to control for the false discovery rate. Compared to the Bonferroni-based methods for controlling family-wise error rate, which prevents incorrect rejection of hypotheses at the cost of highly reduced power, the $\mathrm{BH}$ method presents a better compromise between the need to correct for multiple testing and to maintain high power by ensuring that only a certain proportion of null hypotheses (e.g., 5\%) are falsely rejected. Unless noted

\footnotetext{
${ }^{2}$ We did not test for residual variance as not only is it considered to be nonessential in evaluating group invariance and in particular mean comparisons (Boer et al., 2018), but the value of constraining residual variances to be equal among groups has also been questioned (Little, 2013; Sakauk, 2019).
}

otherwise, the significant effects we report survived after making this adjustment.

In evaluating the model fit, we adjusted the cutoff values based on the quality of the measurement (McNeish et al., 2018), which can affect the interpretation of the "conventional" cutoff values. Put simply, universal application of these cutoffs can be misleading because given the identical structural misspecification, a model with low-quality (vs. high-quality) measurement would in fact show a better fit (see Hancock \& Mueller, 2011 for more information). Thus, we accounted for the measurement reliability (specifically, average standardized loadings; see Sakaluk \& Fisher, 2019) when evaluating model fit as follows: we used the conventional cutoff (CFI $\geq 0.95$ and RMSEA $\leq 0.06$; Hu \& Bentler, 1999) for models with mean standardized loadings of 0.70 (which formed the basis of Hu and Bentler's suggestions), but more liberal cutoff $(\mathrm{CFI} \geq 0.775$, RMSEA $\leq 0.20)$ for models with mean standardized loadings around 0.90 , and more conservative cutoff $(\mathrm{CFI} \geq 0.975$ and RMSEA $\leq 0.02)$ for models with mean standardized loadings of 0.40. Following Chen (2007) and Cheung and Rensvold (2002), we examined the model fit changes, and changes in CFI in particular $(\Delta \mathrm{CFI} \leq-0.01)$, as criteria for evaluating invariance. Although CFI was chosen as the primary criterion, we also report changes in RMSEA; changes larger than 0.015 in RMSEA supplementing changes in CFI above the cutoff would indicate noninvariance.

\section{Results}

\section{Measurement Invariance and Mean Comparisons}

Relationship Status We first examined a configural model, which showed good fit to the data, CFI $>0.99$, RMSEA $=0.00(90 \% \mathrm{CI}=[0.00,0.09])$. We then assessed metric invariance by constraining the factor loadings to be equal across the two groups. The change in the model fit 
Table 3 Descriptive statistics of all study variables and comparisons across relationship status and gender (Study 1)

\begin{tabular}{|c|c|c|c|c|c|c|c|}
\hline & Range & $\begin{array}{l}\text { Single } \\
(n=243)\end{array}$ & $\begin{array}{l}\text { Partnered } \\
(n=246)\end{array}$ & Comparison & $\begin{array}{l}\text { Men } \\
(n=264)\end{array}$ & $\begin{array}{l}\text { Women } \\
(n=223)\end{array}$ & Comparison \\
\hline & & $M(S D)$ & $M(S D)$ & & $M(S D)$ & $M(S D)$ & \\
\hline Sexual satisfaction & $1-7$ & $2.60(1.48)$ & $4.88(1.63)$ & $z=15.75, p<.001$ & $3.45(1.86)$ & $4.06(1.95)$ & $z=-3.57, p<.001$ \\
\hline Solitary sexual desire (Single) & $1-9$ & $5.26(1.73)$ & - & - & $5.40(1.63)$ & $4.90(1.84)$ & MI not supported \\
\hline Dyadic sexual desire & $1-9$ & $5.27(1.52)$ & - & - & $5.45(1.42)$ & $4.96(1.63)$ & MI not supported \\
\hline Solitary sexual desire (Partnered) & $1-9$ & - & $4.77(2.10)$ & - & $5.55(1.59)$ & $4.25(2.23)$ & $z=1.59, p=.11$ \\
\hline Dyadic sexual desire (Partner) & $1-9$ & - & $6.32(1.24)$ & - & $6.42(1.16)$ & $6.25(1.31)$ & $z=1.84, p=.07$ \\
\hline Dyadic sexual desire (Other) & $1-9$ & - & $4.80(2.05)$ & - & $5.68(1.81)$ & $4.09(1.94)$ & $z=3.38, p<.001$ \\
\hline Desired frequency of SSA & $1-7$ & $4.62(1.51)$ & $4.45(1.88)$ & - & $4.57(1.55)$ & $4.51(1.87)$ & - \\
\hline Desired frequency of PSA & $1-7$ & $5.32(1.08)$ & $5.67(0.95)$ & $z=3.22, p=.001$ & $5.59(0.93)$ & $5.38(1.12)$ & MI not supported \\
\hline Actual frequency of SSA & $1-7$ & $4.77(1.58)$ & $4.33(1.93)$ & - & $4.88(1.55)$ & $4.16(1.95)$ & - \\
\hline Actual frequency of PSA & $1-7$ & $2.72(1.67)$ & $5.11(1.24)$ & $z=15.98, p<.001$ & $3.69(1.89)$ & $4.16(1.88)$ & $z=-2.93, p=.003$ \\
\hline
\end{tabular}

SSA = solitary sexual activities; PSA = partnered sexual activities. $M=$ mean; $S D=$ standard deviations. Range refers to possible range for each scale. Latent mean comparisons are reported only for constructs with which measurement invariance (MI) across partnership status or gender was testable and supported. Constructs with which MI testing could not be conducted (i.e., assessed with fewer than three items or with different items for single and partnered participants) are indicated by a dash (-) and those with which MI was tested but scalar equivalence was not achieved are indicated by "MI not supported." For full results of the measurement invariance tests (and mean comparison tests using partially invariant models), please see Supplemental Material

was below the predetermined values for rejecting invariance, $\Delta \mathrm{CFI}=-0.002, \Delta \mathrm{RMSEA}=-0.06$. Adding the constraints on the intercepts also did not result in a significant change in fit, $\Delta \mathrm{CFI}=-0.005, \Delta \mathrm{RMSEA}=-0.03$, suggesting that scalar invariance was supported and that meaningful mean comparisons could be made. As can be seen in Table 3, partnered individuals were more sexually satisfied than single individuals.

Gender The first model assuming configural invariance showed good fit to the data, CFI $>0.99$, RMSEA $=0.00$, $90 \% \mathrm{CI}=[0.00,0.08]$, and the second model constraining the factor loadings did not show a significant change in fit, $\Delta \mathrm{CFI}=-0.001, \Delta \mathrm{RMSEA}=-0.04$, supporting metric invariance. The third model that constrained the intercepts also did not result in a large decrease in CFI, $\Delta \mathrm{CFI}=-0.001, \Delta \mathrm{RMSEA}=-0.008$, allowing us to compare the means between men and women. The data showed that women reported greater sexual satisfaction than men (Table 3). Although these results should be interpreted in light of the greater proportion of partnered individuals among women than men (59\% of women vs. $42 \%$ of men were in a relationship), a two-way ANOVA test examining the effects of both gender and relationship status on sexual satisfaction also indicated that both main effects were significant, $p s<0.001$ (in the absence of a significant interaction), suggesting that being a woman and being in a relationship were independently related to higher sexual satisfaction.

\section{Solitary and Dyadic Sexual Desire and Sexual Satisfaction}

Table 2 shows that at the correlation level, greater solitary desire was associated with lower sexual satisfaction for both single and partnered individuals. Greater dyadic desire was also associated with lower sexual satisfaction for singles. For partnered individuals, as in previous research (e.g., Moyano et al., 2017), partner-specific dyadic desire was associated with greater sexual satisfaction, while dyadic desire involving attractive others was not associated with sexual satisfaction.

Table 4 presents results from regression models examining the extent to which solitary and dyadic sexual desire are uniquely linked with sexual satisfaction among single and partnered individuals. Note that given the differences in how dyadic sexual desire was conceptualized, we examined separate models for single and partnered individuals (rather than testing an interaction). With both types of desire accounted for, only dyadic sexual desire was associated with single individuals' sexual satisfaction such that those with greater dyadic sexual desire reported being less sexually satisfied. On the other hand, both (partner-specific) dyadic and solitary sexual desire were uniquely associated with sexual satisfaction among partnered individuals. Individuals in relationships were more sexually satisfied the greater partner-specific 
Table 4 Solitary and dyadic sexual desire associated with sexual satisfaction (Study 1)
Table 5 Solitary and partnered sexual acts associated with sexual satisfaction (Study 1)

\begin{tabular}{|c|c|c|c|c|c|c|c|c|}
\hline & \multicolumn{4}{|c|}{ Single individuals } & \multicolumn{4}{|c|}{ Partnered individuals } \\
\hline & $\beta$ & $t$ & $p$ & $r_{s}^{2}$ & $\beta$ & $t$ & $p$ & $r_{s}^{2}$ \\
\hline Gender & .05 & 0.76 & .45 & .08 & -.06 & -0.96 & .34 & .01 \\
\hline Age & -.01 & -0.23 & .82 & .00 & -.05 & -0.83 & .41 & .10 \\
\hline Solitary desire & -.01 & -0.08 & .94 & .20 & -.29 & -4.38 & $<.001$ & .16 \\
\hline Dyadic desire & -.34 & -5.10 & $<.001$ & .98 & - & - & - & \\
\hline Dyadic desire (Partner) & - & - & - & & .43 & 6.68 & $<.001$ & .52 \\
\hline Dyadic desire (Other) & - & - & - & & -.11 & -1.58 & .12 & .06 \\
\hline
\end{tabular}

$r_{s}^{2}=$ squared structure coefficient, representing the proportion of variance in the regression effect explained by each predictor, irrespective of collinearity with other predictors. We also reported results from commonality analysis which separates the unique variance explained by each predictor from the shared variance between all combinations of predictors and can help interpreting the regression results, especially in the presence of multicollinearity (Ray-Mukherjee et al., 2014). Gender was coded as $0=$ men and $1=$ women

\begin{tabular}{|c|c|c|c|c|c|c|c|c|}
\hline & \multicolumn{4}{|c|}{ Single individuals } & \multicolumn{4}{|c|}{ Partnered individuals } \\
\hline & $\beta$ & $t$ & $p$ & $r_{s}^{2}$ & $\beta$ & $t$ & $p$ & $r_{s}^{2}$ \\
\hline Gender & -.04 & -0.60 & .55 & .04 & -.04 & -0.70 & .49 & .01 \\
\hline Age & -.03 & -0.43 & .67 & .00 & -.05 & -0.99 & .32 & .05 \\
\hline Want (solitary) & .13 & 1.57 & .12 & .00 & .24 & 2.49 & .01 & .03 \\
\hline Do (solitary) & -.17 & -1.72 & .09 & .07 & -.42 & -4.63 & $<.001$ & .12 \\
\hline Want (partnered) & -.27 & -3.45 & $<.001$ & .37 & -.12 & -1.61 & .11 & .00 \\
\hline Do (partnered) & .26 & 4.29 & $<.001$ & .24 & .62 & 9.99 & $<.001$ & .66 \\
\hline Want $\times$ Do (solitary) & -.05 & -0.68 & .50 & .05 & -.03 & -0.41 & .68 & .00 \\
\hline Want $\times$ Do $($ partnered $)$ & .24 & 3.09 & .002 & .58 & .20 & 4.81 & .001 & .06 \\
\hline
\end{tabular}

$r_{s}^{2}=$ squared structure coefficient, representing the proportion of variance in the regression effect explained by each predictor, irrespective of collinearity with other predictors. Gender was coded as $0=m e n$ and $1=$ women dyadic sexual desire and the less solitary sexual desire they had. Dyadic desire for attractive others was not associated with sexual satisfaction. ${ }^{3}$

\section{Sexual Satisfaction as a Function of Frequency of Wanting and Doing Sexual Acts}

Turning to the findings using frequency-based constructs, Table 2 shows that at the correlation level, doing solo activities more frequently was associated with single individuals' lower levels of sexual satisfaction. Further, both wanting less frequent and doing more frequent partnered sexual acts were associated with greater sexual satisfaction. For partnered individuals, doing less frequent solitary acts and more

\footnotetext{
${ }^{3}$ For all our analyses, we tested whether the effects of interest are moderated by gender, age, as well as sociosexual orientation. We did not find any consistent moderating effects across the two studies, but we have included results on any significant interaction that emerged each study in Supplemental Material.
}

frequent partnered acts were associated with greater sexual satisfaction.

We then examined how desired and actual frequency of solitary and/or partnered sexual acts are uniquely associated with sexual satisfaction as well as if they have an interactive effect. The regression models were estimated separately for singles and partnered individuals, and using robust standard errors (HC3; Long \& Ervin, 2000) to correct for violations of error variance assumptions. Table 5 shows that among single individuals, neither desired nor actual frequency of solitary acts was associated with sexual satisfaction. Higher desired frequency of partnered acts and lower actual frequency of partnered acts on the other hand were independently associated with lower sexual satisfaction. However, the effects of desired and actual frequency of partnered sexual acts were qualified by a significant interaction. Specifically, as illustrated in Fig. 1a, wanting to engage in partnered acts more frequently was associated with lower sexual satisfaction for singles whose current frequency was low ( $1 S D$ below the mean), $\beta=-0.51, t=-3.71, p<0.001$, but not for singles who 
A Single Individuals' Sexual Satisfaction

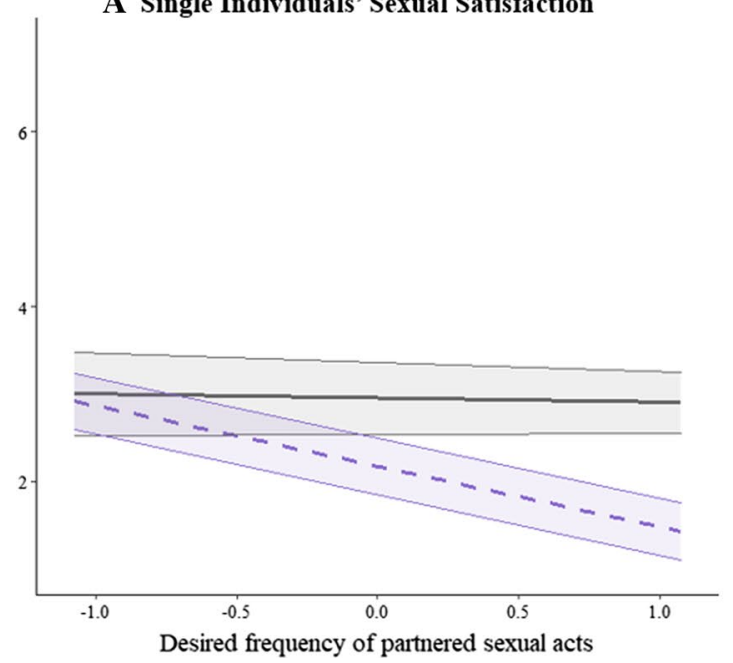

B Partnered Individuals' Sexual Satisfaction

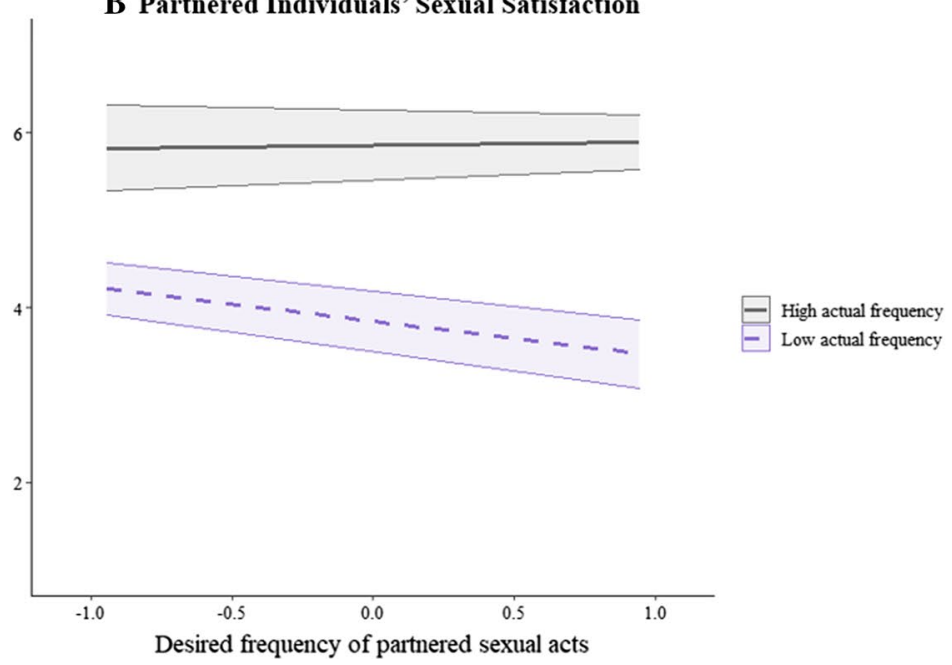

Fig. 1 Interaction between desired and actual frequencies of engaging in partnered sexual acts predicting sexual satisfaction among single (a) and partnered (b) individuals (Study 1). Note. Shaded bands denote 95\% confidence intervals

reported high current frequency of partnered acts ( $1 S D$ above the mean), $\beta=-0.02, t=-0.14, p=0.88$.

Among partnered individuals, both desired and actual frequency of solitary acts were associated with sexual satisfaction such that individuals who want to engage in solitary acts more frequently and/or do them less frequently were more sexually satisfied. With regard to the partnered acts, there was a significant main effect of actual frequency which, as for single individuals, was qualified by an interaction with desired frequency. ${ }^{4}$ As illustrated in Fig. 1b, wanting more frequent partnered acts was associated with lower sexual satisfaction among those who were not engaging in the partnered acts frequently, $\beta=-0.25, t=-2.05, p=0.04$, but not among those who were engaging in partnered activities frequently, $\beta=0.01, t=0.08, p=0.94$.

\section{Summary}

We examined how solitary and dyadic sexual desire and activities are associated with single and partnered individuals' sexual satisfaction, assessed using the Satisfaction with Sex Life Scale-Revised, which demonstrated measurement invariance across relationship status. Among single individuals, desire for solitary sexual activities, whether it was assessed using the SDI-2 or the specific activity items, was not uniquely associated with sexual satisfaction, whereas

\footnotetext{
${ }^{4}$ In Supplemental Material, we also reported results from a model based on a pooled sample that tested moderating effects of relationship status on each of the effect in Tables 5 and 9. The results showed no significant three-way interaction (i.e., Want $\times$ Do $\times$ Relationship status) in either of the study, suggesting that the interactions depicted in Figs $.1,2$ did not significantly differ by relationship status.
}

desire related to partnered sexual activities was consistently associated with lower sexual satisfaction. Similarly, consistent links were found between desire for partnered activities and sexual satisfaction among partnered individuals such that greater desire was associated with greater sexual satisfaction. Importantly, for both single and partnered individuals, an interaction between wanting and doing partnered sexual activities was observed suggesting the negative implications of unsatisfied desire for partnered sexual activities. In Study 2 , we aimed to replicate the findings in Study 1 to increase our confidence in the effects. Further, as the sample primarily consisted of relatively young participants in Study 1, we recruited a sample with a broader age distribution to ensure the generalizability of our effects.

\section{Study 2}

\section{Method}

\section{Participants and Procedure}

Data for this study were collected during the last week of January 2021. We conducted power analyses using G*Power (Faul et al., 2007) based on the size of the interaction effects (desired and actual frequency of partnered act) in the previous study. The minimum sample size necessary to detect such an effect with $90 \%$ power was 275 for single and 398 for partnered individuals. We aimed to recruit a similar number of men and women and also have a relatively equal distribution across four age groups (20 s and younger, $30 \mathrm{~s}, 40 \mathrm{~s}$, and $50 \mathrm{~s}$ and above) in both single and partnered samples. We excluded those who failed attention checks 
Table 6 Correlations between the study variables (Study 2)

\begin{tabular}{lllllllll}
\hline & 1 & 2 & 3 & 4 & 5 & 6 & 7 & 8 \\
\hline 1. Sexual satisfaction & - & $-.11^{* \dagger}$ & $.37^{* *}$ & -.02 & -.09 & $.15^{* *}$ & -.07 & $.61^{* *}$ \\
2. Solitary sexual desire & $-.16^{*}$ & - & $.30^{* *}$ & $.41^{* *}$ & $.74^{* *}$ & $.41^{* *}$ & $.76^{* *}$ & .08 \\
3. Dyadic sexual desire & $-.24^{* *}$ & $.54^{* *}$ & - & $.31^{* *}$ & $.20^{* *}$ & $.55^{* *}$ & $.22^{* *}$ & $.41^{* *}$ \\
4. Dyadic sexual desire (Other) & - & - & - & - & $.28^{* *}$ & $.28^{* *}$ & $.33^{* *}$ & .07 \\
5. Desired frequency of SSA & -.11 & $.77^{* *}$ & $.34^{* *}$ & - & - & $.42^{* *}$ & $.78^{* *}$ & .09 \\
6. Desired frequency of PSA & $-.24^{* *}$ & $.55^{* *}$ & $.75^{* *}$ & - & $.45^{* *}$ & - & $.39^{* *}$ & $.49^{* *}$ \\
7. Actual frequency of SSA & -.08 & $.74^{* *}$ & $.42^{* *}$ & - & $.72^{* *}$ & $.48^{* *}$ & - & $.11^{* \dagger}$ \\
8. Actual frequency of PSA & $.32^{* *}$ & $.20^{* *}$ & $.38^{* *}$ & - & .11 & $.35^{* *}$ & $.22^{* *}$ & - \\
\hline
\end{tabular}

SSA $=$ solitary sexual activities; PSA = partnered sexual activities. Dyadic sexual desire refers to overall dyadic sexual desire for singles and partner-specific desire for partnered individuals. Values below the diagonal indicate correlations among singles and values above the diagonal indicate correlations among partnered individuals

${ }^{\dagger}$ Not significant when adjusting for the false discovery rate (Benjamini \& Hochberg, 1995)

$p^{*}<.05, p^{* *}<.01$

or who indicated having been dishonest in answering the questions. No other exclusion criteria were applied. The final sample consisted of 286 single ( 150 men, 136 women; $M_{\text {age }}=37.72, S D_{\text {age }}=13.59$; range $\left._{\text {age }}=18-79\right)$ and 463 partnered individuals (257 men, 203 women, 2 others; $M_{a g e}=39$, $S D_{\text {age }}=14.54$; range $\left._{\text {age }}=19-79\right) .{ }^{5}$ About half of the participants in relationships were married $(n=224), 157$ were dating, and 79 were engaged. They had been in a relationship for an average of 8 years and 9 months $(\mathrm{SD}=10$ years and 2 months). Participants were fully debriefed about the study aims after completing the survey.

\section{Measures}

The measures were identical to Study 1 . The internal consistencies of the measures were as follows: sexual satisfaction $(\alpha=0.95)$, solitary sexual desire $(\alpha=0.91)$, dyadic sexual desire (for singles; $\alpha=0.90$ ), partner-specific dyadic sexual desire $(\alpha=0.85)$, dyadic sexual desire toward attractive others $(\alpha=0.86)$, desired frequency of solitary sexual acts $\left(r_{s b}=0.94\right)$, desired frequency of partnered sexual acts $(\alpha=0.92)$, actual frequency of solitary sexual acts $\left(r_{s b}=0.95\right)$, and actual frequency of partnered sexual acts $(\alpha=0.97)$.

\section{Results}

Correlations among all study variables are presented in Table 6 . The pattern of results looked largely similar to what we observed in Study 1 (Table 2) although there were some

\footnotetext{
5 The oversampling of partnered individuals was due to the fact that participants who had been recruited based on their profile indicating single status turned out to have started dating and were directed to a survey designed for partnered individuals.
}

differences. Descriptive statistics of all variables, separated by relationship status and gender, as well as the results of their measurement invariance tests are presented in Table 7. As in Study 1, single individuals were on average less satisfied than were partnered individuals. Notably, in contrast to Study 1, we did not find significant gender differences in sexual satisfaction in this study.

\section{Analyses Using the SDI-2}

As summarized in Table 8, only dyadic sexual desire emerged as a significant unique correlate of single individuals' sexual satisfaction such that those with greater dyadic sexual desire were less sexually satisfied. On the other hand, both solitary sexual desire and partner-specific dyadic sexual desire were significantly associated with partnered individuals' sexual satisfaction. Partnered individuals with less strong solitary sexual desire and/or greater partner-specific dyadic sexual desire reported greater sexual satisfaction. This pattern of significant (and non-significant) results successfully replicates our findings in Study 1.

\section{Analyses on the Frequency of Wanting and Doing Sexual Activities}

Table 9 shows that among single individuals, neither desired nor actual frequency of solitary acts was associated with sexual satisfaction. On the other hand, higher actual frequency of partnered acts was associated with greater sexual satisfaction although this main effect was qualified by an interaction with desired frequency of partnered sexual acts. Specifically, as in Study 1, wanting to engage in partnered acts more frequently was associated with lower sexual satisfaction for singles whose current frequency was low, $\beta=-0.49$, $t=-6.40, p<0.001$, but not for singles who reported high 
Table 7 Descriptive statistics of all study variables and comparisons across relationship status and gender (Study 2)

\begin{tabular}{|c|c|c|c|c|c|c|c|}
\hline & Range & $\begin{array}{l}\text { Single } \\
(n=286)\end{array}$ & Partnered $(n=463)$ & Comparison & $\begin{array}{l}\text { Men } \\
(n=407)\end{array}$ & $\begin{array}{l}\text { Women } \\
(n=339)\end{array}$ & Comparison \\
\hline & & $\mathrm{M}(\mathrm{SD})$ & $\mathrm{M}(\mathrm{SD})$ & & $\mathrm{M}(\mathrm{SD})$ & $\mathrm{M}(\mathrm{SD})$ & \\
\hline Sexual satisfaction & $1-7$ & $2.62(1.46)$ & $4.47(1.64)$ & $z=15.83, p<.001$ & $3.75(1.80)$ & $4.79(1.82)$ & $z=-0.38, p=.71$ \\
\hline Solitary sexual desire (Single) & $1-9$ & $4.95(1.86)$ & - & - & $5.43(1.63)$ & $4.43(1.96)$ & MI not supported \\
\hline Dyadic sexual desire & $1-9$ & $5.15(1.59)$ & - & - & $5.60(1.38)$ & $4.63(1.66)$ & MI not supported \\
\hline Solitary sexual desire (Partnered) & $1-9$ & - & $4.66(1.98)$ & - & $5.33(1.69)$ & $3.86(2.03)$ & MI not supported \\
\hline Dyadic sexual desire (Partner) & $1-9$ & - & $5.95(1.33)$ & - & $6.28(1.12)$ & $5.58(1.47)$ & MI not supported \\
\hline Dyadic sexual desire (Other) & $1-9$ & - & $4.79(2.04)$ & - & $5.51(1.80)$ & $3.94(1.96)$ & MI not supported \\
\hline Desired frequency of SSA & $1-7$ & $4.64(1.62)$ & $4.40(1.72)$ & - & $4.72(1.48)$ & $4.21(1.87)$ & - \\
\hline Desired frequency of PSA & $1-7$ & $5.07(1.37)$ & $5.36(1.15)$ & $z=3.02, p=.003$ & $5.66(0.95)$ & $4.74(1.37)$ & MI not supported \\
\hline Actual frequency of SSA & $1-7$ & $4.49(1.81)$ & $4.25(1.88)$ & - & $4.80(1.61)$ & $3.78(1.97)$ & - \\
\hline Actual frequency of PSA & $1-7$ & $2.43(1.66)$ & $4.59(1.44)$ & MI not supported & $3.93(1.77)$ & $3.57(1.94)$ & $z=2.37, p=.02$ \\
\hline
\end{tabular}

SSA = solitary sexual activities; PSA = partnered sexual activities. $M=$ mean; $S D=$ standard deviations. Range refers to possible range for each scale. Latent mean comparisons are reported only for constructs with which measurement invariance (MI) across partnership status or gender was testable and supported. Constructs with which MI testing could not be conducted (i.e., assessed with fewer than three items or with different items for single and partnered participants) are indicated by a dash (-) and those with which MI was tested but scalar equivalence was not achieved are indicated by "MI not supported." For full results of the measurement invariance tests (and mean comparison tests using partially invariant models), please see Supplemental Material

Table 8 Solitary and dyadic sexual desire associated with sexual satisfaction (Study 2)

\begin{tabular}{|c|c|c|c|c|c|c|c|c|}
\hline & \multicolumn{4}{|c|}{ Single individuals } & \multicolumn{4}{|c|}{ Partnered individuals } \\
\hline & $\beta$ & $t$ & $p$ & $r_{s}^{2}$ & $\beta$ & $t$ & $p$ & $r_{s}^{2}$ \\
\hline Gender & -.09 & -1.43 & .16 & .00 & .09 & 1.89 & .06 & .00 \\
\hline Age & -.05 & -0.80 & .42 & .00 & -.23 & -5.26 & $<.001$ & .21 \\
\hline Solitary desire & -.07 & -1.00 & .32 & .39 & -.27 & -5.54 & $<.001$ & .05 \\
\hline Dyadic desire & -.24 & -3.38 & $<.001$ & .85 & - & - & - & - \\
\hline Dyadic desire (Partner) & - & - & - & - & .43 & 9.77 & $<.001$ & .55 \\
\hline Dyadic desire (Other) & - & - & - & - & .00 & 0.04 & .97 & .00 \\
\hline
\end{tabular}

Replicated significant effects of interest are bolded. $r_{s}^{2}=$ squared structure coefficient. Gender was coded as $0=$ men and $1=$ women current frequency of partnered acts, $\beta=-0.08, t=-0.37$, $p=0.71$ (Fig. 2a).

A similar interaction pattern was also replicated among partnered individuals. In addition to the main effects of wanting and doing partnered activities, there was a significant interaction between desired and actual frequency of partnered acts. As illustrated in Fig. 2b, wanting more frequent partnered acts was associated with lower sexual satisfaction among those who were not engaging in the partnered acts frequently, $\beta=-0.29, t=-4.70, p<0.001$, but not among those who were engaging in partnered activities frequently, $\beta=0.03, t=0.41, p=0.68$.

\section{General Discussion}

The present research sought to extend the understanding of single and partnered individuals' sexual satisfaction by examining their sexual desires and activities, both solitary and partnered. To this end, we first compiled a multi-item measure of sexual satisfaction demonstrating measurement equivalence across relationship status (and gender) and examined how sexual desires and activities are associated with single and partnered individuals' sexual satisfaction in two studies. By further examining the interactive effects of wanting and currently doing solitary and partnered sexual activities on 
Table 9 Solitary and partnered sexual acts associated with sexual satisfaction (Study 2)

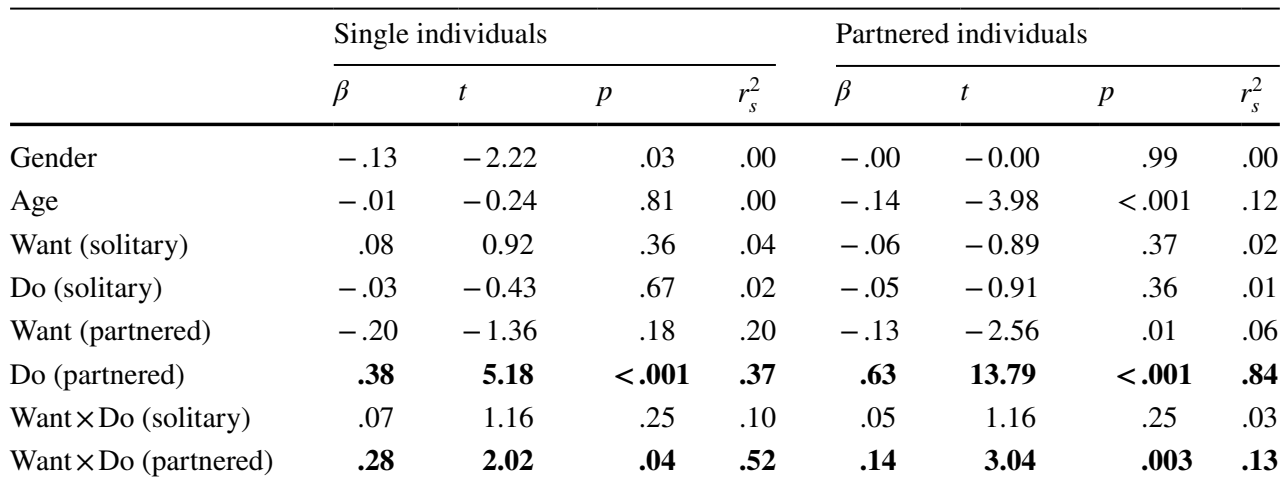

Replicated significant effects of interest are bolded. $r_{s}^{2}=$ squared structure coefficient. Gender was coded as $0=$ men and $1=$ women
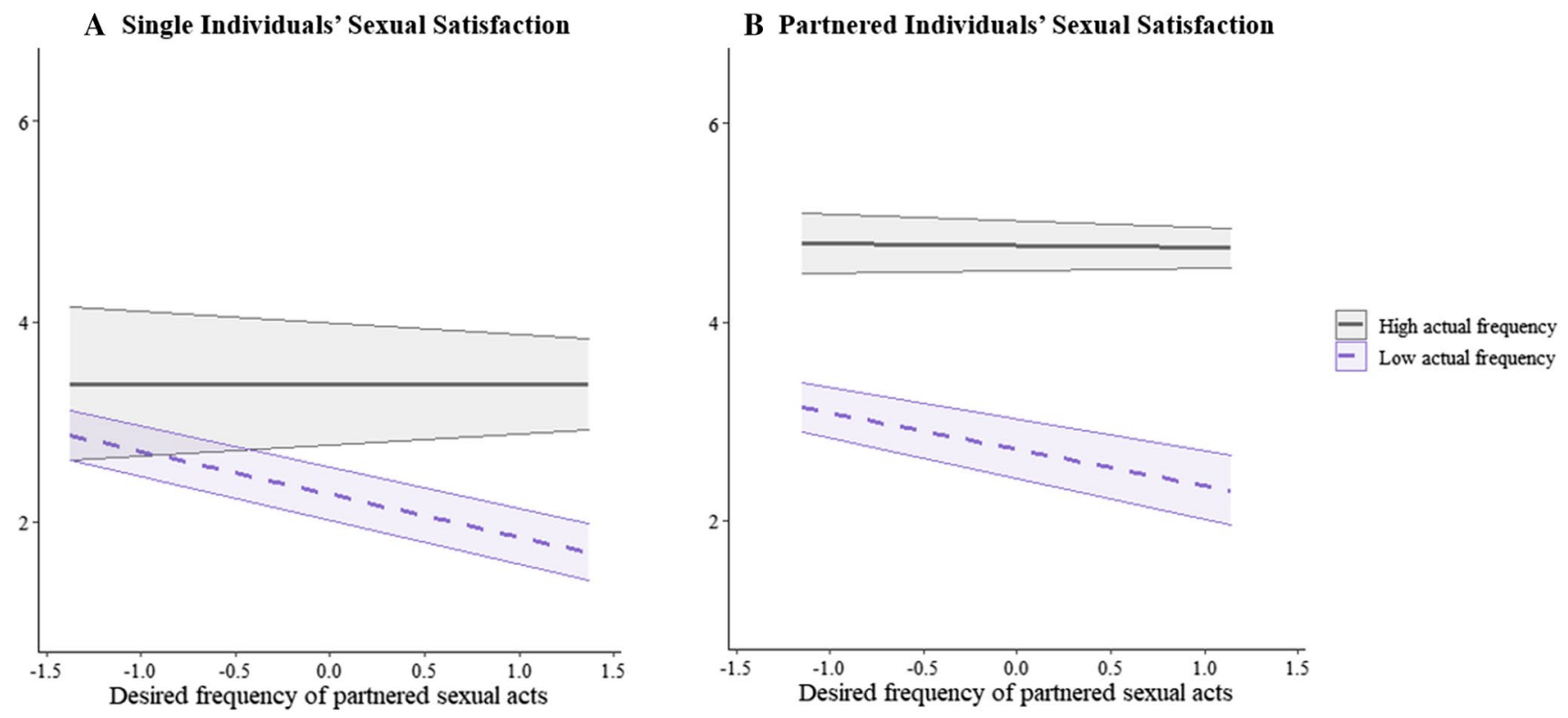

Fig. 2 Interaction between desired and actual frequencies of engaging in partnered sexual acts predicting sexual satisfaction among single (a) and partnered (b) individuals (Study 2). Note. Shaded bands reflect 95\% confidence intervals

sexual satisfaction, the present research extended understanding of what both groups' satisfying sexual lives look like. Our data suggest that for both groups, how much one desires partnered sexual activities carries considerable weight for their evaluation of their sexual lives if they currently lack the experience.

\section{Comparing Single and Partnered Individuals' Sexual Satisfaction}

Across the two studies, we compared single and partnered individuals' sexual satisfaction using the Satisfaction with Sex Life Scale—Revised (composed of items from existing scales). Notably, the conclusions from our comparisons using this refined scale were not different from previous studies (i.e., single individuals were less sexually satisfied than partnered individuals; e.g., Antičević et al., 2017). However, it is important that we were able to assess and establish measurement invariance, which is essential to valid interpretations of the mean-level differences across groups (Sakaluk, 2019) but had been frequently overlooked in the previous research. As sexuality research encompasses a more diverse range of groups (e.g., those in monogamous vs. non-monogamous relationships; Sakaluk et al., 2021) or just as importantly, differentiates subgroups within a group once considered 
homogenous (such as singles), testing and establishing measurement invariance prior to comparisons will be of importance.

Particularly for purposes of comparing across different groups such as single and partnered individuals, we believe that there is value in operationalizing sexual satisfaction as a global evaluation of one's sexual life. Given that what constitutes a satisfying sexual life could vary across different groups (as well as individuals within these groups), it can be useful to let the participants have their own idiosyncratic set of criteria for evaluating overall satisfaction. That is, when the goal is to examine whether disparate individuals or groups feel sexually gratified, a measure that allows for a summary assessment of sexual satisfaction regardless of how people construe the path to sexual gratification may be a useful tool. In our research, we focused on the different types and levels of sexual desires and activities as correlates of such satisfaction and were able to identify some similarities and uniqueness in the way they contribute to each group's sexual satisfaction.

\section{Consistent Effects Across the Two Studies}

\section{Sexual Experiences with Another}

Among single individuals, higher levels of dyadic sexual desire were consistently associated with lower sexual satisfaction, whether it was assessed with SDI-2 or as desired frequency of partnered activities (at the correlational level). When accounting for both desired and actual frequency of engaging in partnered activities, however, the strength of main effects of desired frequency dropped. Instead, there was an interaction between desired and actual frequencies such that wanting more frequent partnered sexual activities was associated with lower sexual satisfaction only if individuals were not participating in the desired activities very frequently. These data suggest that singles with relatively high sexual desire for partnered sexual activities may experience sexual frustration when not able to find sexual partners, which in turn contributes to dissatisfaction with their sex lives (and thus perhaps with their singlehood; Park et al., 2021). On the other hand, singles with low sexual desire (e.g., asexual individuals, e.g., Bogaert, 2015) may fare relatively well in singlehood by sidestepping sexual frustration from unmet needs for partnered sexual activities.

A similar pattern emerged for those in relationships. Consistent with previous research (Moyano et al., 2017), higher levels of partner-specific dyadic desire and of desired frequency of partnered activities were both associated with greater sexual satisfaction. As with single individuals, however, a more interesting pattern was observed when the desired frequency of sexual activities was analyzed along with actual frequency. Desire to more frequently engage in partnered activities was associated with lower sexual satisfaction only for those whose actual frequency was currently low. This suggests that the positive links between partnerspecific sexual desire (from the SDI-2) and sexual satisfaction observed across studies were indicative of the benefits of actual engagement and fulfillment of desire, rather than having desire per se.

Previous literature suggests that, relative to solitary activity, people find partnered sexual activities to be more satisfying (Mah \& Binik, 2002), have considerable desire for them (Santilla et al., 2007), and are more likely to reap relational in addition to sexual benefits from them (including in the context of casual sex; Paul et al., 2008). Thus, it is perhaps not surprising that satisfying desires for partnered sexual activity appears to be a clear and important correlate with sexual satisfaction for both single and partnered individuals.

\section{Sexual Experiences by Oneself}

For single individuals, although zero-order correlations seemed to suggest that higher solitary sexual desire was associated with lower levels of sexual satisfaction, no significant link was found in regression models that accounted for both solitary and dyadic sexual desires. This suggests that the significant link between solitary desire and sexual satisfaction may have been reflecting effects of general sexual desire, rather than desire specific to solitary experiences. With desired frequency of solitary acts, no significant link was found with sexual satisfaction at the correlational level or in regression models. One possibility for our results suggesting no unique effect of solitary experiences might have to do with the correlational nature of our data, which is not suited to capture a potential reciprocal process (e.g., Toates, 2009). That is, although sexual satisfaction was represented as an outcome in our research, high or low levels of sexual satisfaction can also be a cause of certain activities or absence thereof. For example, for those experiencing low sexual satisfaction (e.g., due to a lack of or unsatisfying partnered sexual activities), a readily available means to alleviate the frustration might involve solitary activities (Rowland et al., 2020). Although they are unlikely to be a perfect substitute, there is some evidence that solitary sexual activities can elicit similar types of pleasure as partnered activities (e.g., feelings of getting outside oneself; Goldey et al., 2016) and pleasure from solitary activities may be even stronger in some contexts than that from partnered activities (e.g., orgasm for women; Carvalheira \& Leal, 2013; Wade et al., 2005). Thus, it is possible that solitary sexual acts can provide some gratification to the individual. This then raises the possibility of opposite forces at work, which can obscure the link between solitary desire or activities and sexual satisfaction at the correlational level: low sexual satisfaction motivates 
engagement in solitary sexual activities (i.e., a negative link between frequent solitary sexual acts and sexual satisfaction), which feeds into more positive evaluations of one's sexual life (i.e., a positive link between frequent solitary sexual act and sexual satisfaction).

Of course, there might be other factors in play that were not captured in our research. For example, factors such as guilt or shame around having engaged in solitary activities (Carvalheira \& Leal, 2013; Kaestle \& Allen, 2011) can also complicate the link between desired or actual engagement in solitary activities and sexual satisfaction. That is, any benefits of solitary acts are more likely to manifest when the individual accepts them as a healthy practice; for those not internally endorsing such acts, their costs will be more salient (e.g., Grubbs \& Perry, 2019).

The importance of attitudes toward being sexual by oneself also helps explain our findings regarding partnered individuals' solitary desire. Specifically, one consistent link was found between greater solitary desire (assessed using SDI-2) and sexual satisfaction among partnered individuals in regression models which accounted for both solitary and dyadic desires. That is, independent of not wanting to be sexual with a partner, wanting to be sexual by oneself was uniquely associated with lower levels of sexual satisfaction. At first glance, given that solitary desire is relatively easy to meet, it is surprising that it had negative implications for one's sexual satisfaction. However, it is possible that for those in relationships, having such a desire (even if it is not stemming from some dissatisfying sexual experiences with a partner) might elicit negative feelings to the extent that it is not considered as normative or desirable.

\section{Limitations and Future Directions}

A notable feature of the Satisfaction with Sex Life ScaleRevised in our research was the high internal consistency, which raises concerns about the breadth of the content captured by the four items. This may have to do with the way we had conceptualized sexual satisfaction (i.e., a global evaluation) as measures of satisfaction conceptualized similarly (e.g., life satisfaction) also tend to show very high internal consistency (Diener et al., 2013). In hindsight, this issue could have been addressed to some degree by creating a more diverse initial pool of items. Perhaps with more items extensively capturing, for example, both sexual satisfaction and dissatisfaction that even allow for a test of a potential two-factor structure, we could have compiled a measure with a broader content scope. It is also important to note that the items in our revised scale all center around the phrase "sex life," the meaning of which to our participants we cannot be entirely certain. As such, future qualitative research as to what single and partnered individuals construe as being part of (and not part of) their sex life would be valuable. Thus, along with its strength (e.g., invariance across single and partnered individuals), precisely what is being assessed (and compared across the groups) by this scale needs to be considered in future research using this scale. Further, researchers might want to use an alternative one-item measure when there is limited space; in Supplemental Material, we show that the 4-item scale was very highly correlated with a commonly used single-item measure of sexual satisfaction. However, for the purpose of simultaneously studying single and coupled individuals, we believe that using the four items to compare the two groups' sexual satisfaction has the advantage of allowing a researcher to confirm that the items hang together equivalently across relationship status.

Another caveat to keep in mind when interpreting our results is that all our data were collected in the midst of the social and sexual restrictions of the COVID-19 pandemic. Much research has demonstrated the impact the pandemic has had on people's sexual lives; for example, Lehmiller et al. (2021) found (in a sample primarily from the USA) that the average frequency of both solitary and partnered sexual activities decreased since the pandemic began compared to the past year's frequencies. Likewise, Wignall et al. (2021) found that British young adults' sexual activities decreased overall after the onset of the pandemic and that among those who continued to engage in sexual activity, those who were single or were in a casual relationship tended to report smaller increases in sexual activities than those in a serious romantic relationship. In light of these findings, it is possible to speculate how the pandemic could have affected some of the effects observed in our research. For example, while the general pattern of mean-level differences in sexual satisfaction between single and partnered individuals might not be entirely attributable to the pandemic (e.g., considering similar pre-pandemic findings; Antičević et al., 2017), the existing gap between the two groups could indeed have increased due to the pandemic as the social distancing measures created more barriers to finding a sexual partner for those not living with another person.

Meanwhile, when it comes to the within-group associations (or lack thereof) observed in our research, it is not as easy to make reasonable speculations if and how the pandemic could have affected them. For example, one might have expected solitary sexual activities to play a greater role in single individuals' sexual satisfaction during the pandemic (vs. pre-pandemic) given the decreased partnered sexual opportunities. However, the null association we found also raises the possibility that single individuals' increased loneliness during the pandemic (Hansen et al., 2021) could have increased their desire for physical intimacy with another person that canceled out any benefits of solitary activities. Given the complete post hoc nature of these speculations, we caution against claiming generalizability or period-specificity of 
our findings. As for any studies conducted during this time, the generalizability of our effects warrants replication in the future when the pandemic ends.

Lastly, we also note caution in interpreting the interaction effects in our regression models. What they captured were differences in the strength of the link between desired frequency of sexual acts and sexual satisfaction depending on the actual frequency, rather than effects of "match" between the desire and actual sexual experiences (see Edwards, 2001). To precisely test whether the degree to which the desire is being met is uniquely linked with sexual satisfaction, future research should employ a different analytic strategy (i.e., response surface analysis; Humberg et al., 2019) based on a large sample. It is worth noting, however, that the interpretation of such analysis will need to account for the paucity of data on one direction of the mismatch (i.e., individuals scoring higher on actual frequency of sexual activities than desired frequency).

In future efforts to replicate the present findings, it will be also important to examine how other features of singlehood play a role. For example, some single individuals are voluntarily single or "single by choice" (Adamczyk, 2017) and for many reasons (e.g., social disinterest; Pepping et al., 2018). Further, single individuals vary to a great degree in their ability to find and secure sexual partners. Although we did not find consistent moderation by individual differences, we explored in our studies including age and gender (as well as sociosexuality; see Footnote 3), untested variables including individual (e.g., attractiveness, social goals; Girme et al., 2016) and situational factors (e.g., available pool of potential partners in proximity) should be a focus of future research.

\section{Conclusion}

This research compiled a potentially useful measure of sexual satisfaction applicable to both single and partnered individuals and examined how desire for and engagement in solitary and dyadic sexual activities are related to sexual satisfaction in both groups. Given the particular lack of research investigating single individuals' sexual lives, future research should build on the present results to further explore what this increasing population's sexual needs, deficits, opportunities, and challenges are, especially as we (hopefully) transition out of the COVID-19 pandemic. Longitudinal studies examining questions such as how their sexual experiences (or lack thereof) affect and are affected by their sexual selfperceptions will also be of interest. Lastly, a separate investigation on asexual singles will be essential as it is unclear to what extent our findings around individuals with relatively low sexual desire are representative of this under-explored population (Bogaert, 2015). Overall, however, our data suggested that at least among singles who participated in our survey during the pandemic, gratification of partnered sexual desire may well be a key element of a happy sexual and thus single life.

Supplementary Information The online version contains supplementary material available at https://doi.org/10.1007/s10508-021-02153-y.

Funding This research was supported by a Social Science and Humanities Research Council of Canada (SSHRC) Insight Grant awarded to Geoff MacDonald.

\section{Declarations}

Conflict of interest The authors declare that they have no conflict of interest.

Ethical Approval This research was approved by the Institutional Review Board at the University of Toronto.

Informed Consent We obtained informed consent from all participants included in the study.

\section{References}

Adamczyk, K. (2017). Voluntary and involuntary singlehood and young adults' mental health: An investigation of mediating role of romantic loneliness. Current Psychology, 36, 888-904. https://doi.org/ 10.1007/s12144-016-9478-3

Antičević, V., Jokić-Begić, N., \& Britvić, D. (2017). Sexual self-concept, sexual satisfaction, and attachment among single and coupled individuals. Personal Relationships, 24, 858-868. https://doi.org/ $10.1111 /$ pere. 12217

Benjamini, Y., \& Hochberg, Y. (1995). Controlling the false discovery rate: A practical and powerful approach to multiple testing. Journal of the Royal Statistical Society: Series B, 57, 289-300. https://doi. org/10.1111/j.2517-6161.1995.tb02031.x

Beutel, M. E., Burghardt, J., Tibubos, A. N., Klein, E. M., Schmutzer, G., \& Brähler, E. (2018). Declining sexual activity and desire in men-Findings from representative German surveys, 2005 and 2016. Journal of Sexual Medicine, 15, 750-756. https://doi.org/ 10.1016/j.jsxm.2018.03.010

Blunt-Vinti, H. D., Walsh-Buhi, E. R., \& Thompson, E. L. (2019) Desire and interest. In R. R. Milhausen, J. K. Sakaluk, T. D. Fisher, C. M. Davis, \& W. L. Yarber (Eds.), Handbook of sexuality-related measures (4th ed., pp. 277-296). Routledge.

Boer, D., Hanke, K., \& He, J. (2018). On detecting systematic measurement error in cross-cultural research: A review and critical reflection on equivalence and invariance tests. Journal of CrossCultural Psychology, 49, 713-734. https://doi.org/10.1177/00220 22117749042

Bogaert, A. F. (2015). Asexuality: What it is and why it matters. Journal of Sex Research, 52, 362-379. https://doi.org/10.1080/00224499. 2015.1015713

Brody, S., \& Costa, R. M. (2009). Satisfaction (sexual, life, relationship, and mental health) is associated directly with penile-vaginal intercourse, but inversely with other sexual behavior frequencies. Journal of Sexual Medicine, 6, 1947-1954. https://doi.org/10. 1111/j.1743-6109.2009.01303.x

Byers, E. S. (1999). The Interpersonal Exchange Model of Sexual Satisfaction: Implications for sex therapy with couples. Canadian 
Journal of Counselling and Psychotherapy, 33, 95-111. Retrieved from https://dev.journalhosting.ucalgary.ca/index.php/rcc/article/ view $/ 58618$

Cappell, J., MacDonald, T. K., \& Pukall, C. F. (2016). For new mothers, the relationship matters: Relationship characteristics and postpartum sexuality. Canadian Journal of Human Sexuality, 25, 126-137. https://doi.org/10.3138/cjhs.252-A5

Carvalheira, A., \& Leal, I. (2013). Masturbation among women: Associated factors and sexual response in a Portuguese community sample. Journal of Sex and Marital Therapy, 39, 347-367. https://doi.org/10.1080/0092623X.2011.628440

Chao, J. K., Lin, Y. C., Ma, M. C., Lai, C. J., Ku, Y. C., Kuo, W. H., \& Chao, I. C. (2011). Relationship among sexual desire, sexual satisfaction, and quality of life in middle-aged and older adults. Journal of Sex and Marital Therapy, 37, 386-403. https://doi. org/10.1080/0092623X.2011.607051

Chen, F. F. (2007). Sensitivity of goodness of fit indexes to lack of measurement invariance. Structural Equation Modeling: A Multidisciplinary Journal, 14, 464-504. https://doi.org/10.1080/ 10705510701301834

Cheung, G. W., \& Rensvold, R. B. (2002). Evaluating goodness-of-fit indexes for testing measurement invariance. Structural Equation Modeling, 9, 233-255. https://doi.org/10.1207/S15328007S EM0902_5

Choi, S. W., Gibbons, L. E., \& Crane, P. K. (2011). Lordif: An R package for detecting differential item functioning using iterative hybrid ordinal logistic regression/item response theory and Monte Carlo simulations. Journal of Statistical Software, 39, 1-30. https://doi.org/10.18637/jss.v039.i08

DeLamater, J. D., \& Sill, M. (2005). Sexual desire in later life. Journal of Sex Research, 42, 138-149. https://doi.org/10.1080/00224 490509552267

Diamond, L. M., \& Huebner, D. M. (2012). Is good sex good for you? Rethinking sexuality and health. Social and Personality Psychology Compass, 6, 54-69. https://doi.org/10.1111/j.17519004.2011.00408.x

Diener, E., Inglehart, R., \& Tay, L. (2013). Theory and validity of life satisfaction scales. Social Indicators Research, 112, 497-527. https://doi.org/10.1007/s11205-012-0076-y

Dosch, A., Rochat, L., Ghisletta, P., Favez, N., \& Van der Linden, M. (2016). Psychological factors involved in sexual desire, sexual activity, and sexual satisfaction: A multi-factorial perspective. Archives of Sexual Behavior, 45, 2029-2045. https://doi.org/10. 1007/s10508-014-0467-z

Edelen, M. O., \& Reeve, B. B. (2007). Applying item response theory (IRT) modeling to questionnaire development, evaluation, and refinement. Quality of Life Research, 16, 5. https://doi.org/10. 1007/s11136-007-9198-0

Edwards, J. R. (2001). Ten difference score myths. Organizational Research Methods, 4, 265-287. https://doi.org/10.1177/10944 2810143005

Edwards, M. C., Houts, C. R., \& Cai, L. (2018). A diagnostic procedure to detect departures from local independence in item response theory models. Psychological Methods, 23, 138-149. https://doi.org/10.1037/met0000121

Faul, F., Erdfelder, E., Lang, A. G., \& Buchner, A. (2007). G* Power 3: A flexible statistical power analysis program for the social, behavioral, and biomedical sciences. Behavior Research Methods, 39, 175-191. https://doi.org/10.3758/BF03193146

Fisher, W. A., Donahue, K. L., Long, J. S., Heiman, J. R., Rosen, R. C., \& Sand, M. S. (2015). Individual and partner correlates of sexual satisfaction and relationship happiness in midlife couples: Dyadic analysis of the International Survey of Relationships. Archives of Sexual Behavior, 44, 1609-1620. https://doi.org/10. 1007/s10508-014-0426-8
Girme, Y. U., Overall, N. C., Faingataa, S., \& Sibley, C. G. (2016). Happily single: The link between relationship status and wellbeing depends on avoidance and approach social goals. Social Psychological and Personality Science, 7, 122-130. https://doi. org/10.1177/1948550615599828

Goldey, K. L., Posh, A. R., Bell, S. N., \& van Anders, S. M. (2016). Defining pleasure: A focus group study of solitary and partnered sexual pleasure in queer and heterosexual women. Archives of Sexual Behavior, 45, 2137-2154. https://doi.org/10.1007/ s10508-016-0704-8

Gott, M., \& Hinchliff, S. (2003). How important is sex in later life? The views of older people. Social Science and Medicine, 56, 1617 1628. https://doi.org/10.1016/S0277-9536(02)00180-6

Gray, P. B., Garcia, J. R., \& Gesselman, A. N. (2019). Age-related patterns in sexual behaviors and attitudes among single US adults: An evolutionary approach. Evolutionary Behavioral Sciences, 13, 111-126. https://doi.org/10.1037/ebs0000126

Grubbs, J. B., \& Perry, S. L. (2019). Moral incongruence and pornography use: A critical review and integration. Journal of Sex Research, 56, 29-37. https://doi.org/10.1080/00224499.2018.1427204

Hancock, G. R., \& Mueller, R. O. (2011). The reliability paradox in assessing structural relations within covariance structure models. Educational and Psychological Measurement, 71, 306-324. https://doi.org/10.1177/0013164410384856

Hansen, T., Nilsen, T. S., Yu, B., Knapstad, M., Skogen, J. C., Vedaa, $\varnothing .$, \& Nes, R. B. (2021). Locked and lonely? A longitudinal assessment of loneliness before and during the COVID-19 pandemic in Norway. Scandinavian Journal of Public Health, 49, 766-773. https://doi.org/10.1177/1403494821993711

Howard, M. C. (2016). A review of exploratory factor analysis decisions and overview of current practices: What we are doing and how can we improve? International Journal of Human-Computer Interaction, 32, 51-62. https://doi.org/10.1080/10447318.2015.1087664

Hu, L. T., \& Bentler, P. M. (1999). Cutoff criteria for fit indexes in covariance structure analysis: Conventional criteria versus new alternatives. Structural Equation Modeling: A Multidisciplinary Journal, 6, 1-55.

Hudson, W. W., Harrison, D. F., \& Crosscup, P. C. (1981). A short-form scale to measure sexual discord in dyadic relationships. Journal of Sex Research, 17, 157-174. https://doi.org/10.1080/1070551990 9540118

Humberg, S., Nestler, S., \& Back, M. D. (2019). Response surface analysis in personality and social psychology: Checklist and clarifications for the case of congruence hypotheses. Social Psychological and Personality Science, 10, 409-419. https://doi.org/10.1177/ 1948550618757600

Kaestle, C. E., \& Allen, K. R. (2011). The role of masturbation in healthy sexual development: Perceptions of young adults. Archives of Sexual Behavior, 40, 983-994. https://doi.org/10.1007/ s10508-010-9722-0

Lawrance, K. A., \& Byers, E. S. (1995). Sexual satisfaction in long-term heterosexual relationships: The Interpersonal Exchange Model of Sexual Satisfaction. Personal Relationships, 2, 267-285. https:// doi.org/10.1111/j.1475-6811.1995.tb00092.x

Lehmiller, J. J., Garcia, J. R., Gesselman, A. N., \& Mark, K. P. (2021). Less sex, but more sexual diversity: Changes in sexual behavior during the COVID-19 coronavirus pandemic. Leisure Sciences, 43, 295-304. https://doi.org/10.1080/01490400.2020.1774016

Levine, S. B. (2003). The nature of sexual desire: A clinician's perspective. Archives of Sexual Behavior, 32, 279-285. https://doi.org/10. 1023/A:1023421819465

Lindberg, L. D., \& Singh, S. (2008). Sexual behavior of single adult American women. Perspectives on Sexual and Reproductive Health, 40, 27-33. https://doi.org/10.1363/4002708

Little, T. D. (2013). Longitudinal structural equation modeling. New York, NY: Guilford Press. 
Long, J. S., \& Ervin, L. H. (2000). Using heteroscedasticity consistent standard errors in the linear regression model. The American Statistician, 54, 217-224. https://doi.org/10.1080/00031305.2000. 10474549

Mah, K., \& Binik, Y. M. (2002). Do all orgasms feel alike? Evaluating a two-dimensional model of the orgasm experience across gender and sexual context. Journal of Sex Research, 39, 104-113. https:// doi.org/10.1080/00224490209552129

Mark, K. P., Garcia, J. R., \& Fisher, H. E. (2015). Perceived emotional and sexual satisfaction across sexual relationship contexts: Gender and sexual orientation differences and similarities. Canadian Journal of Human Sexuality, 24, 120-130. https://doi.org/10.3138/ cjhs.242-A8

Mark, K. P., Herbenick, D., Fortenberry, J. D., Sanders, S., \& Reece, M. (2014). A psychometric comparison of three scales and a single-item measure to assess sexual satisfaction. Journal of Sex Research, 51, 159-169. https://doi.org/10.1080/00224499.2013. 816261

Mark, K. P., Toland, M. D., Rosenkrantz, D. E., Brown, H. M., \& Hong, S. H. (2018). Validation of the Sexual Desire Inventory for lesbian, gay, bisexual, trans, and queer adults. Psychology of Sexual Orientation and Gender Diversity, 5, 122-128. https://doi.org/10. 1037/sgd0000260

McNeish, D., An, J., \& Hancock, G. R. (2018). The thorny relation between measurement quality and fit index cutoffs in latent variable models. Journal of Personality Assessment, 100, 43-52. https:// doi.org/10.1080/00223891.2017.1281286

McNulty, J. K., Wenner, C. A., \& Fisher, T. D. (2016). Longitudinal associations among relationship satisfaction, sexual satisfaction, and frequency of sex in early marriage. Archives of Sexual Behavior, 45, 85-97. https://doi.org/10.1007/s10508-014-0444-6

Meston, C. M., \& Trapnell, P. D. (2005). Development and validation of a five factor sexual satisfaction and distress scale: The Sexual Satisfaction Scale for Women (SSS-W). Journal of Sexual Medicine, 2, 66-81. https://doi.org/10.1111/j.1743-6109.2005.20107.x

Michalos, A. C. (1985). Multiple discrepancies theory (MDT). Social Indicators Research, 16, 347-413. Retrieved from https://www. jstor.org/stable/27521298

Milfont, T. L., \& Fischer, R. (2010). Testing measurement invariance across groups: Applications in cross-cultural research. International Journal of Psychological Research, 3, 111-130. https://doi. org/10.21500/20112084.857

Moyano, N., Vallejo-Medina, P., \& Sierra, J. C. (2017). Sexual Desire Inventory: Two or three dimensions? Journal of Sex Research, 54, 105-116. https://doi.org/10.1080/00224499.2015.1109581

Neto, F., \& da Conceição Pinto, M. (2013). The satisfaction with sex life across the adult life span. Social Indicators Research, 114, 767-784. https://doi.org/10.1007/s11205-012-0181-y

Nomejko, A., \& Dolińska-Zygmunt, G. (2014). The Sexual Satisfaction Questionnaire-psychometric properties. Polish Journal of Applied Psychology, 12, 105-112. https://doi.org/10.1515/pjap-2015-0017

OECD. (2019). SF3.1: Marriage and divorce rates [PDF file]. Retrieved from http://www.oecd.org/els/family/SF_3_1_Marriage_and_ divorce_rates.pdf

Orlando, M., \& Thissen, D. (2003). Further investigation of the performance of S-X2: An item fit index for use with dichotomous item response theory models. Applied Psychological Measurement, 27, 289-298. https://doi.org/10.1177/0146621603027004004

Park, Y., Impett, E. A., \& MacDonald, G. (2021). Singles' sexual satisfaction is associated with more satisfaction with singlehood and less interest in marriage. Personality and Social Psychology Bulletin, 47, 741-752. https://doi.org/10.1177/0146167220942361

Paul, E., Wenzel, A., \& Harvey, J. (2008). Hookups: A facilitator or a barrier to relationship initiation and intimacy development? In S. Sprecher, A. Wenzel, \& J. Harvey (Eds.), The handbook of relationship initiation (pp. 375-390). Psychology Press.
Pepping, C. A., MacDonald, G., \& Davis, P. J. (2018). Toward a psychology of singlehood: An attachment-theory perspective on longterm singlehood. Current Directions in Psychological Science, 27, 324-331. https://doi.org/10.1177/0963721417752106

Ray-Mukherjee, J., Nimon, K., Mukherjee, S., Morris, D. W., Slotow, R., \& Hamer, M. (2014). Using commonality analysis in multiple regressions: A tool to decompose regression effects in the face of multicollinearity. Methods in Ecology and Evolution, 5, 320-328. https://doi.org/10.1111/2041-210X.12166

Regan, P. C., \& Berscheid, E. (1999). Lust: What we know about sexual desire. Thousand Oaks, CA: Sage.

Rodrigue, C., Blais, M., Lavoie, F., Adam, B. D., Magontier, C., \& Goyer, M. F. (2015). The structure of casual sexual relationships and experiences among single adults aged 18-30 years old: A latent profile analysis. Canadian Journal of Human Sexuality, 24, 215-227. https://doi.org/10.3138/cjhs.243-A1

Rowland, D. L., Kolba, T. N., McNabney, S. M., Uribe, D., \& Hevesi, K. (2020). Why and how women masturbate, and the relationship to orgasmic response. Journal of Sex and Marital Therapy, 46, 361-376. https://doi.org/10.1080/0092623X.2020.1717700

Sakaluk, J. K. (2019). Expanding statistical frontiers in sexual science: Taxometric, invariance, and equivalence testing. Journal of Sex Research, 56, 475-510. https://doi.org/10.1080/00224499.2019.1568377

Sakaluk, J. K., \& Fisher, A. N. (2019). Measurement memo I: Updated practices in psychological measurement for sexual scientists. Canadian Journal of Human Sexuality, 28, 84-92. https://doi. org/10.3138/cjhs.2019-0018

Sakaluk, J. K., Quinn-Nilas, C., Fisher, A. N., Leshner, C. E., Huber, E., \& Wood, J. R. (2021). Sameness and difference in psychological research on consensually non-monogamous relationships: The need for invariance and equivalence testing. Archives of Sexual Behavior, 50, 1341-1365. https://doi.org/10.1007/ s10508-020-01794-9

Santtila, P., Wager, I., Witting, K., Harlaar, N., Jern, P., Johansson, A. D. A., Varjonen, M., \& Sandnabba, N. K. (2007). Discrepancies between sexual desire and sexual activity: Gender differences and associations with relationship satisfaction. Journal of Sex and Marital Therapy, 34, 31-44. https://doi.org/10.1080/00926 230701620548

Shaw, A. M., \& Rogge, R. D. (2016). Evaluating and refining the construct of sexual quality with item response theory: Development of the Quality of Sex Inventory. Archives of Sexual Behavior, 45, 249-270. https://doi.org/10.1007/s10508-015-0650-x

Smith, A., Lyons, A., Ferris, J., Richters, J., Pitts, M., Shelley, J., \& Simpson, J. M. (2011). Sexual and relationship satisfaction among heterosexual men and women: The importance of desired frequency of sex. Journal of Sex and Marital Therapy, 37, 104115. https://doi.org/10.1080/0092623X.2011.560531

Snell, W. E., Fisher, T. D., \& Walters, A. S. (1993). The Multidimensional Sexuality Questionnaire: An objective self-report measure of psychological tendencies associated with human sexuality. Annals of Sex Research, 6, 27-55. https://doi.org/10. 1007/BF00849744

Snell, W. E., \& Papini, D. R. (1989). The Sexuality Scale: An instrument to measure sexual-esteem, sexual-depression, and sexualpreoccupation. Journal of Sex Research, 26, 256-263. https://doi. org/10.1080/00224498909551510

Solberg, E. C., Diener, E., Wirtz, D., Lucas, R. E., \& Oishi, S. (2002). Wanting, having, and satisfaction: Examining the role of desire discrepancies in satisfaction with income. Journal of Personality and Social Psychology, 83, 725-734. https://doi.org/10.1037/ 0022-3514.83.3.725

Spector, I. P., Carey, M. P., \& Steinberg, L. (1996). The Sexual Desire Inventory: Development, factor structure, and evidence of reliability. Journal of Sex and Marital Therapy, 22, 175-190. https:// doi.org/10.1080/00926239608414655 
Spielmann, S. S., MacDonald, G., Maxwell, J. A., Joel, S., Peragine, D., Muise, A., \& Impett, E. A. (2013). Settling for less out of fear of being single. Journal of Personality and Social Psychology, 105, 1049-1073. https://doi.org/10.1037/a0034628

Stein, P. J. (1975). Singlehood: An alternative to marriage. Family Coordinator, 24, 489-503.

Štulhofer, A., Buško, V., \& Brouillard, P. (2010). Development and bicultural validation of the new Sexual Satisfaction Scale. Journal of Sex Research, 47, 257-268. https://doi.org/10.1080/00224 490903100561

Suh, E., Diener, E., Oishi, S., \& Triandis, H. C. (1998). The shifting basis of life satisfaction judgments across cultures: Emotions versus norms. Journal of Personality and Social Psychology, 74, 482-493. https://doi.org/10.1037/0022-3514.74.2.482

Symonds, T., Boolell, M., \& Quirk, F. (2005). Development of a questionnaire on sexual quality of life in women. Journal of Sex and Marital Therapy, 31, 385-397. https://doi.org/10.1080/00926 230591006502

Toates, F. (2009). An integrative theoretical framework for understanding sexual motivation, arousal, and behavior. Journal of Sex Research, 46, 168-193. https://doi.org/10.1080/002244909027477 68

U.S. Census Bureau. (2020). Table HH-4. Households by Size: 1960 to Present [Excel file]. Retrieved from https://www2.census.gov/ programs-surveys/demo/tables/families/time-series/households/ hh4.xls

van Anders, S. M. (2012). Testosterone and sexual desire in healthy women and men. Archives of Sexual Behavior, 41, 1471-1484. https://doi.org/10.1007/s10508-012-9946-2
Wade, L. D., Kremer, E. C., \& Brown, J. (2005). The incidental orgasm: The presence of clitoral knowledge and the absence of orgasm for women. Women and Health, 42, 117-138. https://doi.org/10.1300/ J013v42n01_07

Wignall, L., Portch, E., McCormack, M., Owens, R., Cascalheira, C. J., Attard-Johnson, J., \& Cole, T. (2021). Changes in sexual desire and behaviors among UK young adults during social lockdown due to COVID-19. Journal of Sex Research, 58, 976-985. https:// doi.org/10.1080/00224499.2021.1897067

Willoughby, B. J., \& Vitas, J. (2012). Sexual desire discrepancy: The effect of individual differences in desired and actual sexual frequency on dating couples. Archives of Sexual Behavior, 41, 477486. https://doi.org/10.1007/s10508-011-9766-9

Yang, C., Nay, S., \& Hoyle, R. H. (2010). Three approaches to using lengthy ordinal scales in structural equation models: Parceling, latent scoring, and shortening scales. Applied Psychological Measurement, 34, 122-142. https://doi.org/10.1177/0146621609 338592

Yen, W. M. (1984). Effects of local item dependence on the fit and equating performance of the three-parameter logistic model. Applied Psychological Measurement, 8, 125-145. https://doi.org/10.1177/ 014662168400800201

Publisher's Note Springer Nature remains neutral with regard to jurisdictional claims in published maps and institutional affiliations. 